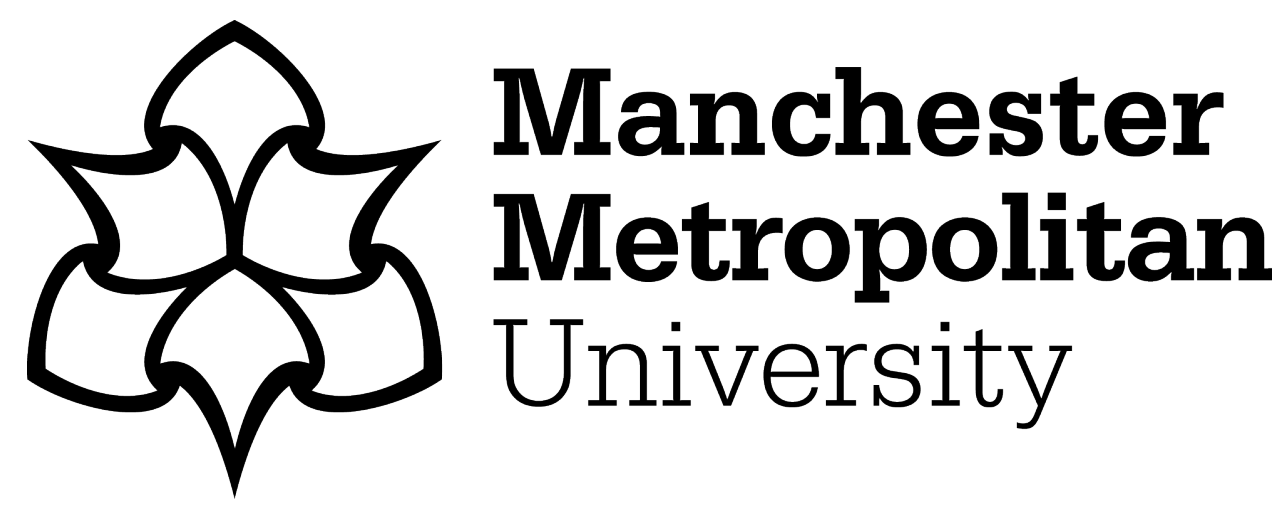

Skinner, HM ORCID logoORCID: https://orcid.org/0000-0002-6505-8073 and Soomers, Pepe (2019) Spiritual tourism on the island of Corfu: Positive impacts of niche tourism versus the challenges of contested space. International Journal of Tourism Anthropology, 7 (1). pp. 21-29. ISSN 1759-0442

Downloaded from: https://e-space.mmu.ac.uk/621233/

Version: Accepted Version

Publisher: Inderscience

DOI: https://doi.org/10.1504/IJTA.2019.098099

Please cite the published version 


\title{
Spiritual tourism on the island of Corfu: positive impacts of niche tourism versus the challenges of contested space
}

\author{
Heather Skinner* \\ Institute of Place Management, \\ Manchester Metropolitan University, UK \\ Email: heatherskinnercorfu@gmail.com \\ *Corresponding author

\section{Pepé Soomers} \\ Corfu, Greece \\ Email: pepesoomers@me.com
}

\begin{abstract}
This paper aims to explore and explain the transformational impact of spiritual tourism on places and their residents. A qualitative case study has been undertaken on the resort of Arillas on the Greek island of Corfu, gathering data from various stakeholder groups in person and via online and social media. Spiritual tourism in Arillas has positively addressed the decline in fortunes experienced by many other resorts on Corfu but has also led to distrust and hostility among various resident groups comprising local people, expatriates, and members of the spiritual community. Implications of this research show that in such contested spaces, well-being needs to be considered not only in financial terms, but also in terms of the impact on all resident stakeholder groups of the physical and societal changes brought about by developments in spiritual tourism, with the well-being needs of any one group not taking precedence over that of others.
\end{abstract}

Keywords: Arillas; Corfu; Greece; mass tourism; all-inclusive; contested spaces; stakeholders; sustainability; spiritual tourism; special interest tourism; alternative tourism.

Reference to this paper should be made as follows: Skinner, H. and Soomers, P. (xxxx) 'Spiritual tourism on the island of Corfu: positive impacts of niche tourism versus the challenges of contested space', Int. J. Tourism Anthropology, Vol. X, No. Y, pp.xxx-xxx.

Biographical notes: Heather Skinner has a successful academic career in the UK. Her current research interest is in the changing nature and changing representations of places, particularly tourism destinations. She is widely published in her main research area of place marketing and place branding. She chairs the annual Corfu Symposium on Managing and Marketing Places, also the Chair of the Institute of Place Management's Visiting Places Special Interest Group, and Co-Chair of the Academy of Marketing's Place Marketing and Branding Special Interest Group. 
Pepé Soomers is an independent researcher. He has always had two strands to his career, one as a photographer, writer, and director for theatre and TV, the other in psychology, coaching and therapy. He has occasionally been able to combine both, writing a book on music therapy for physically disabled people, which resulted in a world tour of seminars, workshops and performances, including one at the US White House for the (old) Bush administration. He is part of a global seminar business team, and has attended, accompanied and organised more than 100 seminars over the last ten years. He is also a member of the Sanyassin community and manages Corfu Buddha Hall.

This paper is a revised and expanded version of a paper entitled 'Spiritual tourism as a 'new' niche market' presented at 2nd Corfu Symposium on Managing and Marketing Places, Corfu, Greece, 27-30 April 2015.

\section{Introduction}

Spiritual tourism is a particular form of niche tourism encompassing several varieties of tourism that overlap the wellness holiday and a variety of religious experiences. This paper aims to explore and explain the transformational impact of spiritual tourism on places and their residents. The place chosen to contextualise this research is the resort of Arillas in the North West of the island of Corfu. Spiritual tourism in Arillas has developed organically rather than as a planned strategic attempt at developing this particular type of niche market. However, the very infrastructure needed to support its development has helped shape and change not only physical aspects of the place itself but has also changed the societal mix of long-term visitors, permanent residents, and the tourist population. This paper first presents some background about the island and its tourism developments in light of changes being made to move away from a declining mass tourism model that is also being evidenced elsewhere across the Mediterranean. The literature review that follows then outlines special interest and other alternative forms of tourism and identifies the role of spiritual tourism as one of the most important niche segments in a growing market for cultural tourism in this context. A framework for identifying some of the challenges of developing spiritual tourism that has arisen from this literature review is then used in order to present the analysis of the qualitative case data.

The sickle shaped Greek island of Corfu is around $64 \mathrm{~km}$ in length and $32 \mathrm{~km}$ at its widest point, occupying in total less than $600 \mathrm{~km}^{2}$, with a population of less than 120,000 , around $40 \%$ live in the main town. Corfu's (predominantly British) expatriate community is estimated to amount to somewhere between $10-15 \%$ of the island's total population (British Vice Consulate, Corfu, 2016). The indigenous population of Corfu overwhelmingly follow the Greek Orthodox religion.

Similar to many other Mediterranean destinations, Corfu's tourism industry has reached maturity, and its mass tourism markets that were developed initially in the 1960s and 1970s are in decline (Skinner, 2017). Although relatively small, the island attracts specific tourism markets to various of its resort destinations. For example, Kavos, in the far south of the island, is known as a party destination that attracts mainly British young people (Williams-Burnett et al., 2016). The North East of the island has gained the epithet 'Kensington-on-Sea' due to the 'rich and powerful' visitors it attracts to the high 
number of luxury villas in the area (Booth, 2008). Other resorts now increasingly rely upon all-inclusive tourists from key source markets such as the UK and Germany to the detriment of their local economy (Skinner, 2017). The Greek National Tourism Organisation (GNTO) and Prefecture of the Ionian Islands, under which Corfu's Municipality falls, has called for the development of more forms of alternative niche tourism to address the decline in mass tourism, and to help extend the island's tourism season (Kaloudis, 2014; Skinner, 2017). The island of Corfu is well-placed to attract special interest tourists through capitalising on the unique elements already in existence that the place can use to target niche tourism markets (Agaliotou, 2015).

However, while evidence suggests that focusing on developing niche tourism can bring positive impacts to a place, even turning around the fortunes of a tourism destination that is losing market share due a decline in mass tourism, there are many challenges to be faced when local communities are reluctant to adopt and embrace change. This leads to destinations becoming contested spaces where residents' well-being needs to be considered not only in financial terms, but also in terms of the impact of physical and societal changes brought about by these developments. This paper therefore explores and explains how spiritual tourism developments in Arillas have, on the one hand, led to positively addressing the decline in fortunes experienced by many other resorts on Corfu, while, on the other hand, have also led to various levels of distrust and hostility among local residents and the resort's business community. This paper also makes another contribution to help fill an important gap in the literature on spiritual tourism, because while this particular niche is a growing area of tourism development in practice it remains not well-researched, understood or theorised.

\section{Literature review}

\subsection{Special interest and alternative forms of tourism}

Since the 1960s and 1970s, Greece has become over-reliant on a mass tourism model (Tsartas, 2003) that is no longer serving the needs of a 21 st century relatively sophisticated and highly competitive global tourism market. The impact of the recent global economic crisis has also impacted on the country, and in particular "the Ionian Islands seem to be the region most severely affected by the crisis in relative terms" [Papatheodorou and Arvanitis, (2014), p.195]. Pursuing various target market segments for special interest rather than mass tourism is often one of the strategies employed by destinations attempting to refocus their tourism efforts. This will often involve directing specific resources to the development of specific niche tourism offerings designed to meet smaller market segments' special interests (Canavan, 2016). Thus, many destinations such as Corfu are focusing more on special interest rather than mass tourism in an attempt to revitalise their tourism offering and reach new albeit smaller niche markets that will allow these destinations to remain sustainable.

Special interest tourism is defined as that which is "developed in places of special interest, where a unique element or attribute related to that place exists" [Agaliotou, (2015), p.293]. A part of special interest tourism is 'alternative tourism' that has, "as a starting point the natural living which is directly linked with the protection of natural environment, the contact with the local communities, the customs and traditions and the preservation of cultural heritage" [Agaliotou, (2015), p.293]. Cultural tourists tend to be 
individuals of higher levels of 'education, income and status', tend to be more active than passive in their engagement with the destinations they visit (Richards, 2011) and "also encourage the establishment and development of businesses owned and controlled by local residents" [Agaliotou, (2015), p.293]. Therefore, targeting cultural tourists (a special interest market that encompasses the niches of spiritual and wellness tourism), would seem to be an effective strategy for destinations seeking to move away from the mass tourism model. While this strategy may possibly result in attracting fewer tourists by destinations aiming to serve smaller niche markets, these types of cultural tourists may be higher spenders than those from a destination's former mass tourism markets.

\subsection{Spiritual tourism}

Richards (2014) identifies spiritual tourism and wellness tourism as two of the most important niche segments of the growing market for cultural tourism. Haq et al. (2008) recognise spiritual tourism as a niche with potential for further growth, noting that an understanding of the different spiritual tourist typologies is needed in order to target each segment of these spiritual tourist consumers with appropriate marketing strategies. Richards (2011) also mentions that "spiritual tourism was identified by the UNWTO as one of the fastest growing travel segments in 2007. However, pinning down this segment is difficult, as it spans a wide range of motivations, from more traditional religious tourism through alternative medicine to tree-hugging".

Studies have categorised spiritual tourism as 'healing', 'experimental', 'quest', 'retreat' and 'collective' (James, 2008), and these themes seem to reflect broader social currents in Western society. Conceptual discussions of leisure or tourism often have spiritual overtones or link leisure with spirituality (Heintzman, 2015; McDowell, 1986). However, while spiritual tourism is a growing area of tourism development in practice (Rao and Pathy, 2015) it is not always well-understood or theorised (Chapman, 2014; Rao and Pathy, 2015). Spiritual tourism is variously defined as "all the religions, religious places associated with, emotional attachment to these centers and infrastructure facilities for the tourists" (Rana, 2015); by Rao and Pathy $(2015$, p.53) as "a type of tourism, where people travel individually or in groups for pilgrimage, missionary, or leisure (fellowship) purposes"; and by Norman $(2011$, p.1) as "tourism characterized by an intentional search for spiritual benefit that coincides with religious practices". Smith and Kelly (2006, p.15) find it noteworthy that many destinations that are successful in attracting holistic tourists are 'aesthetically pleasing, environmentally lush and culturally rich'. Sharpley and Jepson (2011) also find that tourists may seek spiritual experiences and fulfilment particularly in the countryside and in coastal destinations.

The religious tourism market sector has been estimated to be worth upwards of \$18 million dollars, as 300-600 million visitors a year are attracted to visiting religious sites, meaning that it is "no longer a niche market just for low-budget travellers" [Olsen, (2003), p.41]. According to Shackley (2001) 'earth energy' sites would be included within a classification of 'sacred sites' that could be of interest to religious tourists. Examples of such earth energy sites would be the Nazea Lines in Peru, and Glastonbury in England. Glastonbury is situated on one of the most famous earth energy ley line, paths along which various "historical architectural sites have been built" [Gin, (2016), p.105], the St. Michael's Ley, and which, extended as the St. Michael-Apollo Axis, is claimed to run through Corfu. 
It is already accepted that sustainable tourism will be a core driver in the future as destinations shape their image (Yeoman et al., 2007). Voight et al. (2011) found that spiritual tourists tended to have higher education levels than other types of wellness tourists, and to be independent, often solo travellers. When considering issues of sustainability, "spiritual retreat visitors were the most likely to report a long experience of spiritual tourism (over ten years)" [Voight et al., (2011), p.22]. Sustainability and authenticity go hand in hand where communities build a tourism product which belongs to their community (Schlesinger, 2006). However, when a destination's tourism strategy changes so drastically, for example, moving away from mass tourism towards aiming to attract more alternative forms of tourism, encompassing special interest, spiritual, and wellness tourism, there are seen to be many challenges to enable this strategy to work in practice.

\subsection{Challenges of developing spiritual tourism}

Within Greece, the government has announced plans to support the development of wellness tourism as one of the three main sectors of Health Tourism that the Greek National Tourism Organisation (GNTO) should actively promote, and that municipalities should help improve through investment (Greek Travel Pages, 2015). Kiss (2015), however, found three main types of challenges regarding the development of health and wellness tourism in the Balkan region:

- infrastructure challenges, overall poor infrastructure, with outdates facilities and services, in a region typified by financial and political instability and corruption

- business challenges including general levels of mistrust, no traditional culture of business cooperation, lack of skills, professionalism, enthusiasm, engagement, and a general resistance to change

- market challenges of an unknown wellness product, lacking in adequate data and research into wellness tourism, lack of wellness tourism product innovations, and a negative image of wellness tourism in region where 'the persistence of unrestricted smoking in public places (e.g., bars, cafes, restaurants)' is seen by some as another barrier to such tourism development [Kiss, (2015), p.101].

Moreover, such challenges may be more keenly experienced on small island destinations. For example, the Malaysian island of Tioman has faced problems in general tourism development due to the often conflicting interests of various different groups of stakeholders (Ng et al., 2017).

While there were many positive impacts of tourism to island, these should not be pursued at the expense of any one group of stakeholders over another ( $\mathrm{Ng}$ et al., 2017). Thus a more sustainable approach to island tourism developments would appear to be undertaken only when considering both a destination's competitiveness and the quality of life and well-being it offers its communities (Modica and Uysal, 2017), and will be achieved only when tourism development is planned as a collaborative effort, especially to mitigate against 'development from non-local interests' that can be 'perceived by some as threatening well-being and quality of life' [Vogt et al., (2016), p.36]. Small island destinations often have close knit communities, with close proximity of hosts and guests, and close involvement of local residents in tourism businesses. While on the one hand 
identifying and including all stakeholders can be difficult to achieve, on the other hand, not ensuring collaboration can lead to outright conflict, the effects of which are much more heightened in small island communities (Canavan, 2016). The case study that provides the context for this paper will therefore consider both the positive impacts of niche tourism development on the island destination of Corfu, and the negative aspects of distrust and hostility among local residents and local tourism businesses in contested spaces where residents' well-being can be impacted by both the physical and societal changes brought about by these developments.

\section{Method}

A case study method was employed for this research because this method seeks 'to explain some present circumstance' with a 'desire to understand complex social phenomena' [Yin, (2014), p.4]. The single case study focuses on the development of spiritual tourism in the resort of Arillas on the island of Corfu. Multiple data sources were scrutinised that fit with Yin's (2014) classifications of multiple sources of case evidence in order to identity narratives giving voice to the resort's various groups of resident stakeholders. The dominance of quantitative studies in the tourism literature is acknowledged here, however the qualitative approach taken in this research is an attempt to address the calls for more narrative enquiry to be adopted in place-based research (Skinner, 2011). This approach is also in keeping with Brighenti's (2010, p.57) conceptualisation of places that 'de-essentialises territories' and instead focuses more on the myths and narratives that in effect construct the place as lived experiences of those who inhabit and use it (Norberg-Schulz, 1980). However, such an approach to data collection must also ensure the narratives cover all potential groups of resident stakeholders. The sampling approach undertaken was purposive. The authors are both residents of the island; one author is also a member of the spiritual, business and resident community. Therefore, according to our judgement the sample needed to encompass local Corfiot residents (most of whom own or work in tourism related businesses, thus also forming part of the business community), expatriate residents (given the high percentage of expatriate residents of the island, this groups of stakeholders may also encompass some who own or work in local tourism related businesses, and also includes members of the spiritual community), members of the spiritual community (who may be local Corfiots or expatriates, and may or may not be permanent residents of the resort), and tourists (many expatriate residents are former holidaymakers, and some live on the island only during the tourism season, blurring the boundaries somewhat between residents and tourists). Guidance suggests that for such research, between '12-20 data sources generally are necessary' [Onwuegbuzie and Leech, (2007), p.116], rather than individual participants (Kuzel, 1992). Although it is also deemed appropriate to stop collecting data once saturation has been achieved, "in general the old rule seems to hold that you keep asking as long as you are getting different answers" [Baker and Edwards, (2012), pp.3-4].

The data sources sampled encompassed: one set of direct observations from the manager of one of the spiritual centres; two sets of direct observations from members of the resort's Sanyassin community; three depth-interviews with members of the Arillas tourism business community, archival evidence gathered from four articles concerning spiritual tourism in the resort published on two websites that are in the public domain 
(arillas.com and oshonews.com), and 129 comments concerning the development and impact of spiritual tourism made on the closed Arillas Facebook group by three local Corfiot and eight expatriate residents of Arillas, and 24 regular tourists to the resort. A manual textual analysis was undertaken of the case data. In order to somewhat mediate the potential subjectivity of such an analysis approach, the analysis was undertaken thematically, seeking narratives within the data that related to the three challenges identified by Kiss (2015) concerning the development of wellness tourism in the Balkan region, namely infrastructure, business, and market challenges. Due to the contested nature of the development of spiritual tourism in the resort all those who personally contributed to the research were promised complete anonymity, thus any specific comment identified in the findings have been attributed only to either $\mathrm{R}$ (a resident), $\mathrm{T}$ (a tourist), S (a member of the Sanyassin community), or B (a member of the business community). It must be noted that most members of the business community are also residents, some may also be members of the Sanyassin community, so findings have been attributed depending on the focus of the comments made, whether they relate more to the informant's position as a business person, local resident, or Sanyassin community member.

\section{Analysis and discussion of findings}

\subsection{The case of Arillas and the organic development of spiritual tourism}

Arillas is a relatively small village on the coast in the North West of Corfu. The resort has around 400-500 permanent residents from around 46 families, and a tourist season bed capacity of 1,000-1,200. This compares with the more mass tourism resort of Sidari, only around $10 \mathrm{~km}$ away, that has a permanent population of around 250 people, yet a tourism season capacity of 16,000 beds. In Arillas, therefore, both the positive and negative effects of tourism on local residents are felt more closely when local residents comprise such a high proportion of the population of the resort even during the main tourist season. Arillas has attempted to address the challenged of the island's declining tourism market in a number of ways: the resort does not have any big hotels and so has never really focused on the mass tourism market; moreover, most of the accommodation providers prefer to act independently rather than dealing with the larger tour operators. Another key way Arillas has addressed the overall decline in tourism to the island has been through the organic (i.e., unplanned) growth and development of spiritual tourism, particularly (although not exclusively) targeting the German speaking market, and that has contributed an estimated $20-30 \%$ of additional revenue to the resort (B) and thus should be seen as having a positive effect for local resident business people. Many other tourism destinations on the island are now facing an increasingly short season of a little over two months, the high season summer months of July and August, with very limited occupancy outside of this period, and with some businesses opening as late as May and closing in September. Arillas is slowly extending the season from mid-April to the end of October (B). Further extension of the tourism season is limited because there are no direct flights to the island from international airports between the beginning of November and the end of March. While there are a number of events such as local cultural festivals and other music and food/drink related festivals, local business people had begun to complain that their 'regular' guests had difficulty booking their holidays in the high 
season because the spiritual tourists attending 'alternative' events and activities had booked the resort's limited accommodation. For this reason, the managers of the spiritual events began spreading the range of their special interest activities into the shoulder months, with a decision taken to move three of these spiritual festivals to September so there is a better spread of people throughout the entire season (S). This compares starkly with other destinations on the island, for example, Kavos, the 'party capital' of Corfu, where the season is seen to last for only around 10 weeks each year, and where the focus of tourist activities in the place has become reduced to one main bar-filled strip in the resort (Williams-Burnett et al., 2016). However, it was noted that in Arillas "July and August have always been overbooked - not only since spiritual tourism" (B).

Arillas has seen an organic growth in attracting spiritual tourists. How this has come about is explained in an analysis of a summary of the reflections of members of the Sanyassin community. In the early 1970s and 1980s there was a lot of dissatisfaction with the economic and political environment in Europe. Young people did not believe in the establishment of the traditional society anymore and looked elsewhere to find solace. Many went to India to look at Spiritual masters and found the answers to their questions in Osho, a spiritual leader of his time. This movement was called the Raneesj Movement (Idinopulos and Yonan, 1996) After Osho 'left the body' in 1990 his following shattered all over the world and most of them went back to their original countries. Since Osho, or Bagwan as he was called in the beginning of his movement, had this huge following of dissatisfied young people from North West Europe most returned to their homelands after living in India, in the ashram in Poona and the range in Oregon, USA for more than 20 years. Quite a lot of them could not get used to the habits of Europe after such a length of time spent away and tried to find a place that had space for their way of living and that was also cheap because most of the followers, called Sannyasins, did not earn any money or learned a profession in society like others did. Sannyasa is a form of asceticism, marked by renunciation of material desires and prejudices, represented by a state of disinterest and detachment from material life, and has the purpose of spending one's life in peaceful, love-inspired, simple spiritual life (Radhakrishnan, 1922). Corfu was relatively cheap, the weather was nice and reminded the Sanyassins a bit of India, there was lack of a strict system, so things could be created with hardly any money and there was space enough. It simply represented a lot of the factors in life that Sanyassins found important. The first wave of Sanyassins, arriving to the area around 1990, was alien to the local community in Arillas, and local residents would look at them from a distance not trusting the 'guru-people' as they would call them. This changed over time to where the village is now. Many long-term spiritual tourists have ended up buying or renting properties to live in Arillas all year around, or for the entire length of the season, regardless of whether they work in one of the spiritual centres or not, and thus the Sanyassin community is no longer separate from the tourism or local resident community, but rather has become a part of it. This to some extent highlights the issue of the resort as a contested space, where it is becoming difficult to define who is a local resident, and whose well-being is being considered with the development and continued growth of spiritual tourism to the resort. The vast majority of the local Corfiot residents own or work in tourism related businesses. Some are also part of this spiritual community, and some work in the venues that host spiritual tourism activities. However, the expatriate resident community are not all within the spiritual community, many are former holidaymakers who have seen 'their' resort change, and many do not like it. They also feel the behaviour of some spiritual tourists is disrespectful to local Corfiots. For 
example, these sorts of comments are quite commonly found in discussions on social media concerning spiritual tourism to the resort amongst all groups of stakeholders including local Corfiot and expatriate residents, members of the spiritual community, and regular tourists to the resort. The debate continues over whether or not nude sunbathing and nude swimming should be encouraged or permitted, even though it is actually illegal (T).

It happens every year, the Dippy Hippy Germans arrive and glide around the place in flowing cheese cloth, completely off their heads and have no regard for the locals, getting nude and doing yoga on the family beaches in front of the restaurants instead of walking up to the nudist beach!!! (R)

Naked yoga on the beach is not respecting the Greek way of life (R)

I also like nude sunbathing, but I respect the locals and do it in the secluded area. And that's the point: all tourists have to respect the locals - we are all guests in Corfu (T)

I and a number of other persons each year whilst walking on the beach areas either end have been approached and 'instructed' to remove our clothes!! This is my country and neither I nor any visitor will be told or even asked to remove our clothes by anyone $(\mathrm{R})$

Why do these people have to push their 'flowing bullshit' on the rest of the resort and behave like they own the place? [...] they have no respect for the local people and they treat the island like they own it. (R)

Certain of the spiritual events also involve drumming and chanting, and this sparks regular debate on social media about who is responsible for making loud noise that disturbs local residents and other tourists (R) (T), and why other local business must comply with noise abatement measures that are regularly policed throughout the resort, whereas the spiritual tourism community does not seem to comply with this law.

Last year they had one of their drum banging sessions that started at $21.00 \mathrm{hrs}$ and went on through the night until $08.00 \mathrm{hrs}$ the following day. This was held out in the open and could be heard all the way in Afionas. Why is it all the bars and hotels have to reduce their volume at midnight so as not to disturb people in the hotels, who have retired for the evening, yet these inconsiderate 'Free Thinking' people (from any country) get away with disturbing the peace and quiet that Arillas is all about? (R)

The following challenges outlined by Kiss (2015) for the further development of wellness tourism in the Balkans region can also be evidenced when examined from the micro level of the development of spiritual tourism in Arillas, and here our findings show how Arillas has overcome these challenges and also where there is still scope for addressing these challenges further:

\subsection{Infrastructure challenges}

Three years ago, the local business community in Arillas undertook a survey of 900 tourists to consider ways of improving the tourism offering, and overwhelmingly their response can be summarised as "Please don't change anything and keep it authentic". Authenticity, a word often used when it comes to a holiday experience and destinations, lies in the fact that Arillas was a long-forgotten gem on the North West side of the island without a decent infrastructure. Until the beginning of 2000 there was no 
paved road going to the village, only a dirt track. There had also been no big touristic wave happening in Arillas as had been seen across many other places on the island. Arillas, instead, grew as a destination in other ways, and has maintained that focus, not building large hotels, and thus not serving the mass tourism model.

Arillas now has six spiritual centres/clubs, there are three others in nearby villages. Some of these centres have taken over former regular tourism facilities, others have created new buildings specifically to serve the needs of the growing spiritual tourism market. The Alexis Zorba's, Uranus and Mythos centres all cater for a mainly German speaking market. All three clubs also offer all-inclusive holidays that include spiritual activities, accommodation and food. This is unfortunately not so good for the local economy as little tourism expenditure ends up with local Greek businesses. However, these centres do employ local Corfiot workers, and also rent out accommodation for their guests from local Corfiot businesses. Corfu Buddha Hall has grown into the most international centre on the island where spiritual activity leaders from around the world bring their groups to the hall. The hall is rented per week and has only a small bed capacity, so most visitors stay in the local accommodations of Arillas which is good for the local economy. In this centre, local Greek people also work in the kitchen or in the garden. Gayatri Mandir - has become a very successful festival venue. The Mandir in its peak season provides a lot of work to the local community. When the biggest annual festival takes place, there is no accommodation or room left empty in the village and the shortage of space also creates a challenge for the other centres that are dependent on local accommodation to house their groups. This has also pushed up the price of accommodation across the resort during the festival period, which can make it difficult for local businesses to serve the needs of their non-spiritual tourism markets who may have been coming the resort for many years. Dharma Centre - is owned and run by a Swiss French Sanyassin from Geneva to provide workshops for her French speaking friends and clients. Dharma Corfu offers accommodation and food and is not very profitable for the local community since it makes hardly any use of the amenities of the village.

On average, each club houses between 25 to 150 people per week to take part in various activities, although some festivals can attract over 500 people.

There are three other initiatives in the direct vicinity of Arillas. Two centres in Agios Georgios, which is the next bay to Arillas, and one in Kavvadades a village up in the hills from Arillas. The two in Agios Georgios are predominately German speaking and also visited by Germans and the one in Kavvadades is a yoga centre for French speaking people. All three centres provide housing and food and have their own private all-inclusive community. Where other centres are open to the general public these are not.

The growth in the number of these centres, and the increase in the proportion of spiritual tourists they attract to the resort are also seen by some to be having a detrimental effect on other groups of residents and on local businesses.

I think a lot of local establishments saw these tree huggers as much needed extra business during the recession. However these guys don't spend...end of. Indeed they give nothing to the bars and restaurants. The pathetic often very well to do flowing robes stand on the street [....] listen to the live music the bar has paid for whilst dancing about like '60s throwbacks. Do they buy a drink? No... the business people of Arillas need a plan to keep these groups to a sensible level. (R) 
In discussions with other local business owners, we do not object to a few retreats where alternative therapies are taking place. I certainly believe that yoga, meditation, tai chi etc are beneficial to the individual as are many other forms of exercise, etc. Arillas became home to a few centres that have now been here for many years and are part of the community. The various practices and therapies generally did not interfere with or disturb the existing and regular clientele that came to Arillas. However there are now several centres and they seem to be increasing year on year. One lady from one of the groups, challenged me by claiming that they had brought 500 extra guests per week to Arillas who rent the hotel rooms and apartments. This is fervently untrue because Arillas has hardly any more accommodation units and beds than it had before. In reality the members of these groups have simply rented the accommodations that our regular guests or other guests had previously booked and if the groups were not here the accommodations would quickly be filled with other people. (B)

A balance is important but what I see is that the balance is being destabilised, as I say, not because there are alternative therapy groups here, but because of the number of them and the fact that some of their practices are encroaching on the holidays of other guests and the lives of some of the locals. (T)

The response from the spiritual community residents who also run spiritual retreat businesses tends to be similar to that below:

Hopefully it should be possible to create boundaries that allow everyone to enjoy their life or holidays in this village, but it would need the effort to reach out in a constructive way instead of reacting and aggressively give names. [...] We just moved here one year ago, with the intention to grow our food and make music, support the local community and leave a simple life. (S)

Debates also range in the resort about other infrastructure aspects, for example, to make the beach area and its' esplanade 'car free' which means an adjustment in the infrastructure and parking lots to be built. Moreover, some spiritual tourists arriving during the high season set up makeshift camp sites on the beach and in the olive groves because there is not the bed capacity in the resort to deal with a massive influx of additional tourists in high season. While there has been some collaboration concerning the timing of various spiritual festivals and events, not all those who are involved have spread out their events into the shoulder months, leading to extra pressure on the tourism infrastructure and tensions between the spiritual tourists and other 'regular' tourists who may have been coming as repeat visitors to the resort for many years. Greece also remains in financial crisis. Additional taxes are levied on homeowners and tourism businesses each year. The local Corfiot business community and many local residents are concerned that some of the organisations set up to serve spiritual tourism are not legally constituted, and do not always pay their due tax. Thus, not necessarily serving the local community through their ability to contribute financially to the overall improvement of the island or resort's infrastructure. On the other hand, claims are levied at local business people that tax evasion is to some extent embodied in Greek culture, and that local Corfiots are similarly not paying all due taxes.

\subsection{Business challenges}

More than 20 years ago the local people would look at 'the hippies' like strangers, many now work with each other and are friends. 
"I remember seeing groups of strange people in colourful robes walking down to the beach, or when my father and I went out fishing in our boat early in the morning we would see them all dressed in white sitting on the beach and chanting, or dancing wildly. But we didn't see much of them (we locals nicknamed them 'gurus', or 'gurudes' in Greek); they apparently valued their privacy and were obviously not interested in mingling with us." (R)

Time has consciously and sustainably merged two cultures in one. The local community took its time to come to the centres. First, they wouldn't interfere with the 'hippies' or 'Guru people' and it took many years for them to be perceived as a normal part of village life, and also for local people to visit the different centres for a concert or an activity. Some of the centres like Corfu Buddha Hall organise a regular community activity day where they provide activities, recitals, dances and Greek food and music. It is open to all and free of charge and in that way they want to thank the local community for their warm welcome. This also helps for the two cultures to blend and in the same time respect each other. Yet, still to this day there remains a basic lack of trust between the various stakeholders. Greek people in these kinds of villages were brought up with a strong sense of family, so we 'take care of ourselves'. What you see in general in villages like Arillas is a lack of communication between stakeholders and a reluctance when it comes to innovation and to collaboration. Such conservatism and lack of trust sometimes makes new developments in Arillas almost impossible. There is a local business club that talks about these issues but not all of the people who own businesses contribute to the decisions made by the business club.

\begin{abstract}
"The well-established and trained business people snub the Gurus (this is how they call them) because they realise that the Gurus 'drive away' their high-end clients simply by their appearance, their attitude, etc. ... Some other businessmen consider the 'Gurus' to be a lifeline in the economic crisis the country is going through. They may even fill their accommodation or 'entrust' their management to one of the spiritual centres". (B)
\end{abstract}

Thus, while it is often claimed that local businesses hate spiritual tourism, that may not actually be the case: "what they do not like is the way it works in Arillas - it is not in the hands of the locals and so the locals are afraid that they are losing control" (B), and this can be likened to the lack of control local business owners felt about the large tour operators in the early years of tourism development on the island. "First they were afraid of all-inclusive, now they are afraid people will end up eating all together in only one restaurant - the spiritual clubs are acting like all-inclusive" (B). Indeed spiritual tourism in the resort "is mostly run by people who are not members of the local business community" (B), "some locals think that the 'spiritual-festival-organisers' are making millions" (B), and "every new spiritual visitor who comes to visit our area has the hope to open his own small holistic activity or even a new spiritual club" (B). Thus also recognising that, rather than achieving collaboration "even the spiritual centres are competing with each other" (B). "The Arillas society is divided with different opinions from the locals but also from the English and German expats who live here and the 'spiritual' businessmen who are unethically competing with each other ... it's getting worse every year" (B). The growth of Arillas as a special spiritual destination did not come from one special site, church or building and it is still relatively new to the community. "While some are scared that 'the new people' will take over even though that, quite uniquely, didn't happen in Arillas" (S). 


\subsection{Market challenges}

There is still reluctance in Arillas to embrace the concept of wellness in general. For example, almost all restaurants and bars still allow smoking inside, which is not only against the law, but also seems to be in direct contradiction with wellness tourism. There is also not enough choice of vegetarian or vegan food available in the resort because that type of food, often preferred by spiritual tourists, is almost the opposite of Greek cuisine. Both the regular tourists and more conservative business community want to see Arillas known as an ideal destination for a visitor who wants the authenticity of a Greek island holiday, and not as a pilgrimage resort, or as a specific destination for any form of alternative or special interest tourism. As summarised by members of the business community: spiritual tourism in Arillas is no longer 'alternative', it's actually becoming more like mass tourism. 'Alternative' should stem from the local culture, not something imposed upon it, it should stem from the resort's food, uniqueness, and its 'Greekness' (B).

There is also resistance from the Church afraid that residents will lose their culture and religion to this new age spirituality. As an 'April Fool' joke, a story was posted on an Arillas website on 1 April 2017 headlined "Monks and Gurus at our beach". The story was accompanied by a picture photoshopped to show orange robe clad visitors on Arillas beach, and claimed that the Arillas community was bringing a group of monks from Asia for the next few years to help teach locals 'zen and zin', to "help the community gain a better understanding of the life in an economical crisis", and to help keep the beach and resort clean from rubbish. "Their payment will be: free living under the olive groves and free Asian-vegetarian food at the local Tavernas. If this experiment succeeds we are going to introduce it to the next near-by resorts and hotels".

Although the pictures and story were accepted for the April Fool's joke it was by most, some local Corfiot and expatriate residents believed it to be true and the incident caused a certain amount of uproar in the resort, albeit short-lived (R) (T).

Some of the regular tourists feel the spiritual tourists are taking over 'their' resort, and the beach in particular: "I just hope these Gurus don't take over our beloved Arillas too much" (T); "I for one have been going to Arillas for over 21 years now and more and more of them are doing there chanting on the beach and there definitely is more volume of these group people - I'm not against them, but sometimes you can feel that they are taking over the village as if it were their sacred place" (T); "Have often seen groups doing green mud, quasi-religious ceremonies, etc." (T); "They are usually German and come from Zorbas...often there chanting, doing clay, etc.... and taking over the whole beach" (T); "I'm very easy-going, but the only thing that annoys me is the fact that they completely take over and dominate the place. I may have been there peacefully minding my own business for hours and they seem totally oblivious of the disturbance they cause when they suddenly turn up" (T).

The key issues regarding the growth of spiritual tourism in Arillas, and its effect on resident's well-being can be seen summarised by the views of one local Greek businessman:

Have they bothered to ask the business owners who have guests that come for the peace a quiet? I certainly don't object to a few meditation or yoga groups but the reality is that they have taken over half the resort and are changing, not only the identity, but the dynamic of the area and that can't be permitted. I had a number of complaints from guests about this sort of thing last year and I don't 
intend to put up with it this year. One event with drums is acceptable but multiple dates with drums chanting and screaming isn't going to happen!! (B)

In conclusion, this final comment was made from a regular tourist who spends many weeks each year in the resort:

\begin{abstract}
At the end all this is the decision of some of the locals and their look to the future of Arillas: do they want to make quick and easy money or do they want future planning and sustainable marketing, which respects and supports Greek tradition of hospitality without losing their own identity which we all love? If what's happening now in Arillas goes on and on and this wonderful place will change into an Ashram, Arillas will be an interchangeable place, a little Bali or Poona in Greece. Do we want that? Is it in the interest of the locals? I think it's time to think about that! (T)
\end{abstract}

\title{
5 Conclusions
}

There are many forms of special interest tourism, and therefore it is also stressed that each destination "needs to focus on ... differentiation ... define its own niche markets and serve them accordingly ... in order to be able to achieve a unique 'tourist product benefit' which would enable them to establish their position in the global tourism market", and most importantly, achieve this in a way that means this position becomes sustainable and does not cause any further societal or environmental degradation [Sotiriadis and Varvaressos, (2015), p.330]. Such strategic development to address the problems facing the island of Corfu build a sustainable tourism model for the future should therefore involve focusing less on mass tourism models, and more on alternative and niche markets encompassed under what is referred to as 'special interest tourism', and make these a source of competitive advantage for each of its destination resorts, based upon the niche markets each chooses to serve. Corfu is well-placed to attract special interest tourists through capitalising on the unique elements already in existence (Agaliotou, 2015). Of particular interest to this paper, the unique attributes of Corfu, compared with other Mediterranean destinations in general, even other of the Greek Islands, that the place can use to target this market for special interest tourism include its earth energy sites along the St. Michael-Apollo Axis ley line (Shackley, 2001), and its critical mass of spiritual and wellness centres that have grown around the Arillas area. Corfu in general, and the resort of Arillas in particular, also has an abundance of the natural elements that tend to make destinations successful in attracting spiritual tourists, plenty of coast and beautiful countryside (Sharpley and Jepson, 2011), in an 'aesthetically pleasing, environmentally lush and culturally rich' location [Smith and Kelly, (2006), p.15]. Not only is such a focus on special interest activity tourists who may wish to engage in aspects of cultural tourism, and in particular spiritual tourism, targeting a growing tourist market (Haq et al., 2008; Rao and Pathy, 2015; Richards, 2011, 2014), but this is a market typified by higher education and income level (Richards, 2011) independent (Smith, 2003), often solo, travellers (Voight et al., 2011), who are seeking transformational experiences as much as these tourists may have an attendant transformational effect on the place itself. Whereas other special activities may involve relatively short-lived trends or fads, spiritual tourists tend to be those who are a more sustainable target market in the longer term (Voight et al., 2011). This is leading the resort of Arillas and its surrounding areas to be able to grow and develop a niche market 
that is benefiting the local community both culturally and economically through its transformational impact on the place (Geary, 2008). However, the issue of residents' well-being remains problematic when considering contested spaces such as the resort of Arillas. Firstly, it becomes problematic to define who is a 'resident' in this resort, because the 400-500 people who live in the place more or less permanently are not all Corfiots, but also include international expatriates, and also members of the Sanyassin community. Many of these non-Corfiots will have been former holidaymakers, or only live on the island during the tourism season, and this also blurs the boundaries somewhat between residents and tourists. Moreover, the local business tourism community will also comprise people from all three of these groups. However, when it comes to spiritual tourists, even though the business community does receive many positive impacts from its growth in the resort, and the infrastructure has improved for the benefit of all residents, there remain issues of discontent amongst various groups of stakeholders, as also found by $\mathrm{Ng}$ et al. (2017) when researching tourism developments in a small Malaysian island.

Some local resident business people believe that the development and growth of spiritual tourism in Arillas has had a positive and much needed impact on the place at least financially. This is very important to the fortunes of local residents because spiritual tourism to Arillas is bringing in 'an estimated 20-30\% of additional revenue to the resort' on an island that is seeing a general decline in tourism and tourism expenditure. However, some local business people are ambivalent to the matter, and believe that this particular niche could easily be replaced with no detriment to tourism bookings at least in the height of the season, because "July and August have always been overbooked - not only since spiritual tourism". "If the groups were not here the accommodations would quickly be filled with other people". Moreover, many of the spiritual centres to not contribute much to the local economy anyway, and they and their guests tend to keep themselves to themselves, and do not integrate with others in the resort. They look different as they "glide around the place in flowing cheese cloth". They engage in different activities that also set them apart from other resident and tourist groups because they tend to enjoy naked yoga, nude sunbathing, drumming and chanting. However, while some local business people believe that "the Gurus 'drive away' their high-end clients simply by their appearance, their attitude, etc. ... Some other businessmen consider the 'Gurus' to be a lifeline in the economic crisis the country is going through". The resident Sanyassin community in Arillas mostly do not perceive there to be the same problems that other resident groups perceive, and truly believe they have been welcomed and are now seen as much a part of the community as other resident groups. Yet many expatriate residents and tourists continue to see the spiritual tourists as interlopers who are changing the identity of the resort.

In the case of Arillas, the needs of the spiritual tourism community and non-local business people who serve them tend to be overshadowed by the needs of the 'regular' tourists and local businesses who serve that market. The key issue seems to be that the growth of spiritual tourism, that arose organically, and unplanned in Arillas, is changing the very identity of the resort. It is not developing a niche tourism product that has any real authentic connection with the Greek way of life, and indeed some residents (local Corfiots and expatriates) are fearful for the destruction of their way of life. It seems that any perceived financial benefits on the one hand, can be perceived to be outweighed by the loss of identity of Arillas as a small authentic Corfiot/Greek resort. 
Yet, overall, tourism in Arillas has benefited from this form of niche market. Additional income is coming to the resort, the season is longer and more profitable that in many other resorts around the island. There is integration of foreign nationals with the local community, and for the most part, spiritual tourism is having a positive effect. However, what is of concern to all stakeholders is the sustainability of the current form of niche tourism, and its potential for further development. Many are wary that such developments will destroy the very 'Greekness' of the resort, and that this form of tourism, not really built on an authentic cultural heritage, is not what the resort should be known for as its tourism brand develops.

In summary therefore, and as a way of addressing the three key challenges identified by Kiss (2015) to developing such tourism in this region:

- Infrastructure challenges remain. There is not enough bed capacity to further develop the resort in high season without building more accommodation that would destroy the nature of the place. Rife tax evasion means that businesses are not contributing as fully as they should back to the Municipality and National government, which impacts on the well-being of all residents. The season in Arillas is longer than in many other resorts on Corfu. However, there is still plenty of accommodation capacity in the spring and autumn months when there are still direct international flights to the island. There would not need to be much additional accommodation built to accommodate more tourists if these could be attracted to events in April and May, and in September and October. The calendar of spiritual festival activities has been spread somewhat, but there is scope to spread this further. In this way, local resident business people might indeed see the positive benefits of spiritual tourists in filling up their under-utilised accommodation capacity.

- Business challenges also remain. While there is now scope for collaboration between all groups of stakeholders, and the local business association is a good forum to facilitate this, it does not happen. There instead remains mistrust between the various groups. Thus, any sustainability or development of such forms of niche tourism remain hampered by dysfunctional and limited attempts at cooperation that is then impacting negatively on local all three groups of local residents. The resident Sanyassins are not always welcomed into tourism development discussions, expatriate residents who have been former 'regular' tourists feel 'their' place is in danger of being taken over, the Church is wary of what they see as a new religion threatening their very existence and the cultural fabric of the resort, and the business community is torn between those who are making profit from and engaging with spiritual tourism, and those who see it as yet another threat, that is becoming akin to all-inclusive mass tourism and therefore having similar negative impacts. More should be done to encourage communication and collaboration between different resident groups. The Business Association must become more proactive about attracting members from the non-Greek business community, and then to give them a voice, and listen to them. Incentives could be arranged between the spiritual centres and local restaurants to address the problems that these centres are seen as all-inclusive enclaves that do little for the local economy. The centres could be encouraged to open their doors to let in other groups of residents, following the lead of that taken by Corfu Buddha Hall. Outside of the high season, the clubs could stage activities and events to attract more of the other resident groups. This would lead to a 
better spirit of openness, and to more understanding between the resident groups about each other's activities, and also help allay concerns.

- Market challenges can be overcome through better training and education for business people. Seminars could be organised by the local business association, or by the municipality. There is currently no destination marketing organisation for Corfu, and there has not been much specific tourism strategy for the island. Both of these issues should be addressed, and indeed are now being discussed - however, it is questionable if all resident groups are being included in these discussions, and this is an area of concern although it is commendable that such efforts are now being made to consider the various tourism strategies open to the island.

This paper has considered both the positive and negative impacts of the niche market of spiritual tourism to residents' well-being in the Corfiot island resort of Arillas. In doing so it has made a theoretical contribution to our understanding of spiritual tourism that had been recognised as a gap in the extant literature. It has also made a practical contribution by shedding light on the complexities of addressing the infrastructure, business and market challenges faced by such tourism development in contested spaces.

Future research could be undertaken in Corfu to understand if other resorts face similar issues of contested spaces as they pursue different niche markets. Research could also be undertaken of spiritual tourism developments in other Mediterranean island destinations to find areas of commonality in how such developments are managed especially in contested spaces to ensure the well-being of all different resident groups is taken into account.

While this paper has focused on matters of specific relevance to the island of Corfu and resort of Arillas in particular, the issues raised could equally apply to many other island tourism destinations, especially those that have reached the maturity stage of the tourism product lifecycle with their key source markets. Many such destinations are focusing more on special interest and alternative activity tourism rather than mass tourism in an attempt to revitalise their tourism offering and reach new markets that will allow these destinations to remain sustainable, but this brings with it change that is not always perceived as positive by local residents.

\section{References}

Agaliotou, C. (2015) 'Reutilization of industrial buildings and sites in Greece can act as a level for the development of special interest/alternative tourism', Procedia - Social and Behavioural Sciences. Vol. 175, Special Issue: Proceedings of the 3rd International Conference on Strategic Innovative Marketing (IC-SIM 2014), pp.291-298.

Baker, S.E. and Edwards, R. (2012) How Many Qualitative Interviews is Enough?, National Center for Research Methods [online] http://eprints.ncrm.ac.uk/2273/ (accessed 30 March 2018).

Booth, R. (2008) 'Business and pleasure at Kensington-on-Sea', The Guardian, 25 October 2008 [online] https://www.theguardian.com/travel/2008/oct/25/corfu-rothschild-russia-osbornetravel (accessed 13 December 2017).

Brighenti, A.M. (2010) 'On territorology: towards a general science of territory', Theory, Culture and Society, Vol. 27, No. 1, pp.52-72.

British Vice Consulate, Corfu (2016) Corfu British Community Meeting, 23rd November 2016, Ipsos. 
Canavan, B. (2016) 'Tourism stakeholder exclusion and conflict in a small island', Leisure Studies, Vol. 36, No. 3, pp.409-422.

Chapman, M.D. (2014) 'Book review: Spiritual Tourism: Travel and Religious Practice in Western Society by Alex Norman (2011) Continuum Advances in Religious Studies', International Journal for the Study of New Religions, Vol. 5, No. 2, pp.193-196.

Geary, D. (2008) 'Destination enlightenment: branding Buddhism and spiritual tourism in Bodhgaya, Bihar', Anthropology Today, Vol. 24, No. 3, pp.11-14.

Gin, J. (2016) 'Fundamental pattern and consciousness', Cosmos and History: The Journal of Natural and Social Philosophy, Vol. 12, No. 2, pp.99-113.

Greek Travel Pages (2015) Local Authorities Get Involved in Promotion of Greek Health Tourism [online] http://news.gtp.gr/2015/04/13/local-authorities-getinvolved-in-promotion-of-greekhealth-tourism/ (Accessed 13 April 2015).

Haq, F., Wong, H.Y. and Jackson, J. (2008) 'Applying Ansoff's growth strategy matrix to consumer segments and typologies in spiritual tourism', Paper presented at the 8th International Business Research Conference, UAE.

Heintzman, P. (2015) Leisure and Spirituality: Biblical, Historical, and Contemporary Perspectives, Baker Academic, Grand Rapids.

Idinopulos, T.A. and Yonan, E.A. (Eds.) (1996) The Sacred and its Scholars: Comparative Methodologies for the Study or Primary Religious Data, E.J. Brill, Leiden.

James, W. (2008) The Varieties of Religious Experience: A Study in Human Nature, Longmans, London.

Kaloudis, N-F. (2014) 'Destination branding: the case of Corfu', Proceedings of the $1^{\text {st }}$ Corfu Symposium on Managing \& Marketing Places, 14-17 April, Corfu.

Kiss, K. (2015) 'The challenges of developing health tourism in the Balkans', Tourism, Vol. 63, No. 1 , pp.97-110.

Kuzel, A.J. (1992) 'Sampling in qualitative inquiry', in Crabtree, B.F. and Miller, W.L. (Eds.): Doing Qualitative Research: Research: Methods for Primary Care, Vol. 3, pp.31-44, Sage, Newbury Park, CA.

McDowell, J. (1986) 'Singular thought and the extent of inner space', in Pettit, P. and McDowell, J. (Eds.): Subject, Thought and Context, Clarendon Press, Oxford.

Modica, P. and Uysal, M. (Eds.) (2017) Sustainable Island Tourism: Competitiveness and Quality of Life, CABI, Wallingford; Boston.

Ng, S.I., Chia, K.W., Ho, J.A. and Ramachandran, S. (2017) 'Seeking tourism sustainability a case study of Tioman Island, Malaysia', Tourism Management, February, Vol. 58, pp.101-107.

Norberg-Schulz, C. (1980) Genius Loci: Towards a Phenomenology of Architecture, Rizzoli, New York.

Norman, A. (2011) Spiritual Tourism: Travel and Religious Practice in Western Society, Continuum International Publishing Group, London; New York.

Olsen, D.H. (2003) 'A scalar comparison of motivations and expectations of experience within the religious tourism market', International Journal of Religious Tourism and Pilgrimage, Vol. 1, No. 1, pp.41-61.

Onwuegbuzie, A. and Leech, N. (2007) 'A call for qualitative power analysis', Quality and Quantity, Vol. 41, No. 1, pp.105-121.

Papatheodorou, A. and Arvanitis, P. (2014) 'Tourism and the economic crisis in Greece - regional perspectives', Région et Développement, Vol. 39, pp.183-203.

Radhakrishnan, S. (1922) 'The Hindu Dharma', International Journal of Ethics, Vol. 33, No. 1, pp.1-22.

Rana, V. (2015) 'Motives and experiences of foreign (yoga \& spiritual) tourist visiting Rishikesh', International Journal for Research in Education, Vol. 4, No. 1, pp.1-7. 
Rao, P.S. and Pathy, S.N. (2015) 'Market segmentation - key to identify spiritual tourist', International Journal of Multidisciplinary Research Review, Vol. 1, No. 1, pp.53-60.

Richards, G. (2011) 'Cultural tourism trends in Europe: a context for the development of cultural routes', in Khovanova-Rubicondo, K. (Ed.): Impact of European Cultural Routes on SMEs' Innovation and Competitiveness, pp.21-39, Council of Europe Publishing, Strasbourg.

Richards, G. (2014) Tourism Trends: The Convergence of Culture and Tourism, Academy for Leisure, NHTV University of Applied Sciences, The Netherlands.

Schlesinger, V. (2006) Kawaza Village Tourism Project: Authentic Village Visits [online] $\mathrm{http}$ ://www.gonomad.com/2764-kawaza-village-tourism-projectauthentic-village-visits (accessed 13 April 2015).

Shackley, M. (2001) Managing Sacred Sites, Continuum, London; New York.

Sharpley, R. and Jepson, D. (2011) 'Rural tourism: a spiritual experience?', Annals of Tourism Research, Vol. 38, No. 1, pp.52-71.

Skinner, H. (2011) 'An archaeological excavation into the fields of place marketing and place branding', in Patterson, A. and Oakes, S. (Eds.): Proceedings of the Academy of Marketing Conference 2011: Marketing Fields Forever, Academy of Marketing, Liverpool.

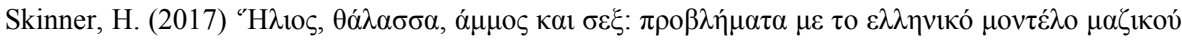

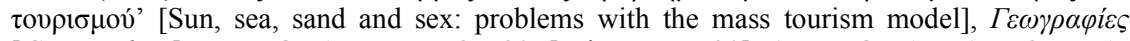

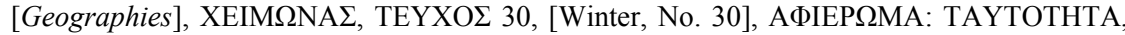
MAPKETIГK KAI BRANDING TOП $\Omega$ N [Special issue on Identity, Marketing and Branding of Places].

Smith, M. (2003) 'Holistic holidays: tourism and the reconciliation of body, mind and spirit', Tourism Recreation Research, Vol. 28, No. 1, pp.103-108.

Smith, M. and Kelly, C. (2006) 'Holistic tourism: journeys of the self', Tourism Recreation Research, Vol. 3, No. 1, pp.15-24.

Sotiriadis, M.D. and Varvaressos, S. (2015) 'A strategic analysis of the greek leisure tourism: competitive position, issues and challenges', Mediterranean Journal of Social Sciences, Vol. 6, No. 1, pp.319-322.

Tsartas, P. (2003) 'Tourism development in Greek insular and coastal areas: sociocultural changes and crucial policy issues', Journal of Sustainable Tourism, Vol. 11, Nos. 2-3, pp.116-132.

Vogt, C., Jordan, E., Grewe, N. and Kruger, L. (2016) 'Collaborative tourism planning and subjective well-being in a small island destination', Journal of Destination Marketing \& Management, Vol. 5, No. 1, pp.36-43.

Voight, C., Brown, G. and Howat, G. (2011) 'Wellness tourists: in search of transformation', Tourism Review, Vol. 66, Nos. 1-2, pp.16-30.

Williams-Burnett, N., Skinner, H. and Fallon, J. (2016) 'Reality television portrayals of tourists behaving badly', Journal of Travel and Tourism Marketing, first published online 20 December 2016, DOI 10.1080/10548408.2016.1261757.

Yeoman, I., Brass, D. and McMahon-Beattie, U. (2007) 'Current issue in tourism: the authentic tourist', Tourism Management, Vol. 28, No. 4, pp.1128-1138.

Yin, R.K. (2014) Case Study Research: Design and Methods, 5th ed., Sage Publications, Thousand Oaks, California. 